European

Neurology
Eur Neurol 2005;54:240-241

DOI: $\underline{10.1159 / 000090721}$
Received: September 6, 2005 Accepted: November 9, 2005 Published online: January 6, 2006

\title{
A Portrait of Myasthenia Gravis?
}

\author{
Valmantas Budrys \\ Clinics of Neurology and Neurosurgery, Vilnius University Faculty of Medicine, Vilnius University \\ Santariskiu Klinikos Hospital, Vilnius, Lithuania
}

\section{Key Words}

Myasthenia gravis $\cdot$ Portrait

\begin{abstract}
The paper presents a work of art showing a presumably myasthenic patient painted more than 50 years before the disease was first described.
\end{abstract}

Copyright $\odot 2005$ S. Karger AG, Basel

Most of neurological diseases are dynamic in nature and only few could be more or less credibly depicted in a static artwork. Among the latter is myasthenia gravis due to facial features and expression that are typical of the disease. As for the visual diagnostic credibility, portraits of real people are more accurate compared to fictional images. The credibility of depiction also relies on the artist's talent. The present article - to the author's knowledge for the first time in the medical literature - presents a work of art showing a presumably myasthenic patient painted more than 50 years before the description of the disease by Samuel Wilks in 1877 and Wilhelm Heinrich Erb in 1878.

Myasthenia gravis is an autoimmune neuromuscular disorder associated with antibodies binding to acetylcholine receptors. This leads to decreased numbers of postsynaptic muscle acetylcholine receptors and impairment of nerve impulse transmission at neuromuscular junctions. Typical clinical features: fluctuating fatigability and weakness of skeletal muscles. Weakness of the levator palpebrae or extraocular muscles is present in more than $90 \%$ of cases and leads to diplopia and asymmetric drooping of the eyelids (ptosis) usually accompanied by weakness of eye closure [1]. Unilateral painless ptosis without ophthalmoplegia will most often prove to be due to myasthenia. Facial mobility and expression are altered. The natural smile becomes flattened or transformed into a snarl $[1,2]$. The voice fades and becomes nasal after sustained conversation. Weakness initially related to ocular and bulbar muscles later becomes generalized in the majority.

Does the lovely portrait of an unknown Italian man (fig. 1) painted by Kanutas Ruseckas (Rusiecki), the wellknown 19th century Lithuanian artist during his study in Rome (1823), demonstrate myasthenic features and could it be assumed to be a portrait of a myasthenic patient?

We can note almost all visual textbook features of myasthenia in this portrait: (1) marked asymmetrical ptosis (left eye almost closed with characteristically visible eyelashes); (2) conspicuous attempts to open eyes clearly visible due to highly elevated eyebrows - very impressive dynamic myasthenic feature in the static picture! (when a healthy subject intentionally closes one eye, the ipsilateral eyebrow simultaneously goes down), and (3) characteristic flattened or 'snarling' smile.

\section{KARGER \\ Fax +41613061234 E-Mail karger@karger.ch} www.karger.com
(C) 2005 S. Karger AG, Base 0014-3022/05/0544-0240\$22.00/0

Accessible online at: www.karger.com/ene
Assoc. Prof. Valmantas Budrys, MD, PhD

Clinics of Neurology and Neurosurgery, Vilnius University Faculty of Medicine

Vilnius University Santariskiu Klinikos Hospital

Santariskiu 2, LT-08661 Vilnius (Lithuania)

Tel./Fax +370 52365 220, E-Mail valma@takas.lt 
1

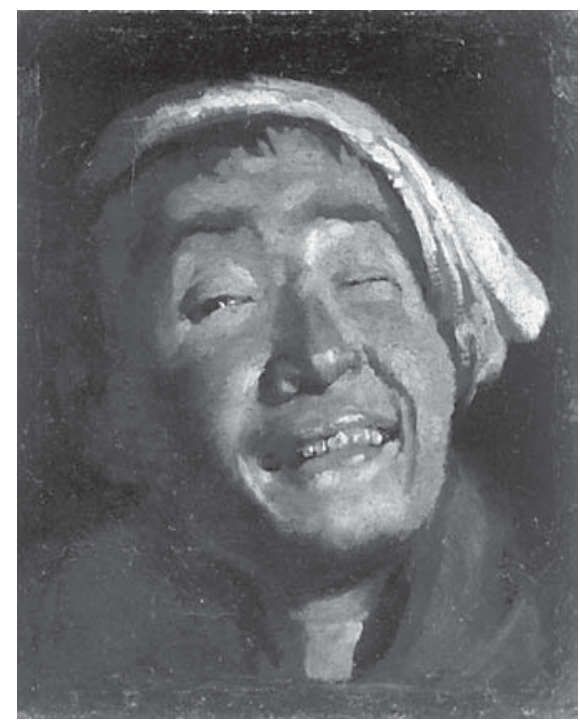

2

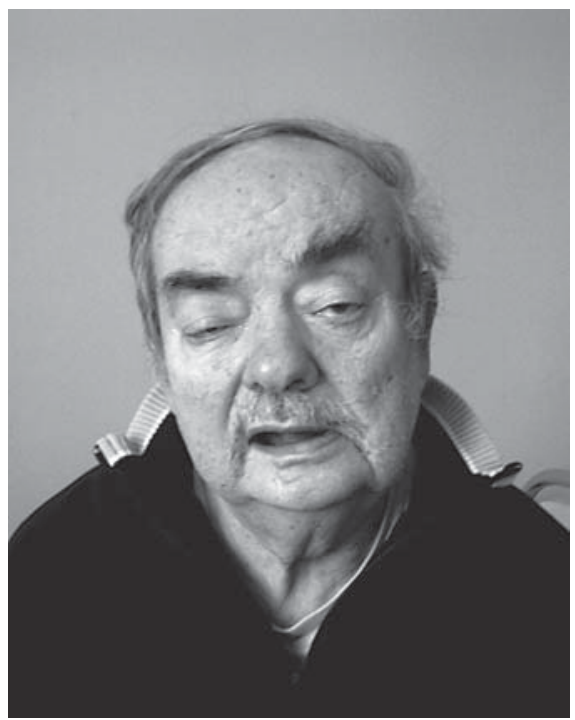

Fig. 1. Smiling Italian, Kanutas Ruseckas, 1823 (reproduced with permission from Lithuanian Art Museum, Vilnius, Lithuania).

Fig. 2. Patient A.K. with a verified diagnosis of myasthenia gravis. Center of Neurology, Vilnius University Santariskiu Klinikos Hospital (reproduced with the patient's permission).
For comparison figure 2 presents a photograph of a patient with a verified diagnosis of myasthenia gravis; there is surprising similarity in marked ptosis, attempts to overcome it by elevating eyebrows and 'snarling' myasthenic smile.

In summary, the artist captured and depicted myasthenic features, naturally knowing nothing about the possible diagnosis of the man immortalized in this masterpiece. Myasthenia gravis, of course, is only presumptive, as we cannot prove it electroneuromyographically or by finding acetylcholine receptor antibodies. Anyway, this portrait is so suggestive that one could use it as a textbook illustration of myasthenia gravis.

\footnotetext{
References

1 Myasthenia gravis and related disorders of neuromuscular transmission; in Adams RD, Victor M, Ropper AH: Principles of Neurology. New York, McGraw-Hill, 1997, pp 14591475.

2 Drachman DB: Myasthenia gravis. N Engl J Med 1994;330:1797-1810.
} 